\title{
OBTENÇÃO DE CORANTES NATURAIS A PARTIR DE ANTOCIANINAS EXTRAÍDAS DE FRUTAS E LEGUMES
}

\section{SHEMINY FREITAS ZAHREDDINE ${ }^{1}$; MARIA DE FÁTIMA DE MENDES PAIXÃO ${ }^{2}$;EMILLY ADORNO DE LIMA VASCONCELOS ${ }^{3}$.}

\author{
1.Bolsista Pibic/Fapesb, Graduanda em Engenharia de Alimentos, Universidade Estadual de Feira de Santana, e-mail: \\ sheminyfsaa@hotmail.com \\ 2.Orientadora, Departamento de Ciências Exatas, Universidade Estadual de Feira de Santana, e-mail: \\ fpaixão100@gmail.com \\ 3.Participante do projeto, Graduanda em Engenharia de Alimentos, Universidade Estadual de Feira de Santana, e-mail: \\ millyadorno95@gmail.com
}

\section{INTRODUÇÃO}

PALAVRAS-CHAVE: Antocianina; extrato; corante.

Segundo a legislação brasileira, Resolução - CNNPA n 12, de 1978, as balas são constituídas basicamente por açúcares fundidos, com ou sem adição de outros ingredientes, de consistência dura ou semidura, podendo apresentar recheio, cobertura, formatos e consistências variadas (ZIMKE, 2014). Nos dias atuais as balas de gelatinas tornaram-se bastante conhecidas, sendo muito bem aceita pelo público jovem. Balas de goma saborizadas com suco de frutas podem ser encontradas no mercado brasileiro, funcionando como uma inovação tecnológica. Situação que também pode ser vista no processamento de confeitos, consistindo em uma boa alternativa para adequação das indústrias de confectionery, tendências globais de alimentação (OLIVEIRA et al., 2015).

Corantes são aditivos alimentares definidos como toda substância que confere, intensifica ou restaura a cor de um alimento. Existem três categorias de corantes permitidas pela legislação, a saber: corantes naturais, corante caramelo e corantes artificiais Esta última pertence a uma classe de aditivos sem valor nutritivo, introduzidos nos alimentos e bebidas com o único objetivo de conferir cor, tornando-os mais atrativos. Seu uso é justificado exclusivamente através do ponto de vista comercial e tecnológico. Os corantes artificiais permitidos no Brasil são o amarelo crepúsculo, azul brilhante FCF, bordeaux $\mathrm{S}$ ou amaranto, eritrosina, indigotina, ponceau $4 \mathrm{R}$, tartrazina e o vermelho 40 , e a legislação exige que o alimento ou bebida que contenha esse tipo de corante apareça em seu rótulo a expressão "colorido artificialmente" (CONSTANT, STRINGHETA E SANDI,2002; PRADO E GODOY, 2003 ).

A aparência de um produto é um fator importante na hora de se tomar a decisão para sua compra, mas estudos revelam que não basta apenas uma boa imagem, os consumidores estão cada vez mais conscientes sobre saúde e bem estar. Além disso, há uma busca crescente, por parte dos consumidores, por uma alimentação mais saudável, o que impulsiona a inovação para uso de ingredientes naturais que atendam as exigências do mercado. Corantes naturais são pigmentos extraídos de fontes naturais e têm a finalidade de conferir, intensificar ou padronizar a coloração de produtos alimentícios. Os principais corantes naturais utilizados no Brasil são: urucum, cúrcuma, luteína, clorofila, páprica, caroteno natural, antocianinas, beterraba, carbo vegetabilis (carvão vegetal), entre outros (FOOD INGREDIENTS BRASIL $\mathrm{N}^{\mathrm{o}} 18,2011$ ).

As antocianinas, juntamente com os carotenóides, representam a maior classe de substancias coloridas do reino vegetal, sendo encontradas em muitas flores e frutos, sendo consumidas pelos seres humanos desde tempos remotos (FOODS INGREDIENTS BRAZIL $N^{\circ}$ 9, 2009). São encontradas em grande número de espécies de plantas, algumas das quais já foram experimentadas como fonte industrial em potencial. Os subprodutos da indústria da uva 
e do vinho já são empregados na preparação comercial de antocianinas (CONSTANT, STRINGHETA E SANDI, 2002).

Além do $\mathrm{pH}$, a cor dos extratos de antocianinas depende de outros fatores como concentração, tipo de solvente usado para sua extração, temperatura, estrutura do pigmento, presença de substâncias capazes de reagir reversível ou irreversivelmente com a antocianina, entre outras. Entretanto, o pH é certamente o fator mais importante no que diz respeito à coloração das antocianinas (CONSTANT, STRINGHETA E SANDI,2002).

Os corantes estão entre os avanços mais polêmicos da indústria de alimentos, pois seu uso justifica-se apenas por questões de hábitos alimentares (visualização do alimento). Sob o ponto de vista toxicológico vários estudos têm sido realizados para verificar os efeitos nocivos ao ser humano, já que esses aditivos não são totalmente inofensivos à saúde. Os corantes artificiais estão sempre na mira das investigações científicas devido às reações adversas que alguns consumidores podem apresentar (PRADO E GODOY, 2003).

O objetivo desse trabalho foi pesquisar corantes naturais provenientes de antocianinas para uso em alimentos, a partir da obtenção das três cores básicas, a saber: amarelo, azul e vermelho.

\section{MATERIAL E MÉTODOS}

A obtenção do corante foi feita a partir da extração aquosa do pigmento, a quente e/ou a frio, por maceração com almofariz e pistilo ou por aquecimento. A proporção usada entre material sólido e solvente foi de 1:3, conforme trabalho realizado por TERCI E ROSSI (2004). Para preparação da base para teste da cor e do sabor, realizou-se a hidratação da gelatina sem sabor e sem cor, misturando-se $6 \mathrm{~g}$ de gelatina em pó com $50 \mathrm{~mL}$ de água, para uso no teste de cor, ou em $50 \mathrm{~mL}$ de suco para teste do sabor, com aquecimento posterior por 15 a 25 segundos para que houvesse a completa dissolução da gelatina. O teste para cor e sabor na bala de gelatina foram realizados separadamente. Para o teste de cor, após retirar a base de gelatina da placa de aquecimento, adicionou-se gotas do corante até atingir a coloração desejada. Em seguida, o líquido foi colocado em forminhas e levado para resfriar em geladeira por cinco minutos (gelatinização). No caso teste do sabor, o líquido (suco + gelatina) foi retirado do aquecimento, colocado diretamente nas forminhas e levado para resfriamento por igual período de tempo. O teste em conjunto de cor e sabor introduzidos na bala de gelatina foi realizado através do processo de hidratação da gelatina sem sabor e sem cor, misturando-se a mesma massa de gelatina em pó supracitada, adicionando-se $50 \mathrm{~mL}$ de suco. Em seguida, a mistura foi aquecida para completa dissolução da gelatina. Na sequência, foram adicionadas gotas do extrato utilizado como corante, até que fosse atingida a coloração desejada. A mistura colorida foi distribuída em forminhas, levada para resfriar em geladeira por cinco minutos (gelatinização).

\section{RESULTADOS E/OU DISCUSSÃO}

Foram testadas, para uso como corante, frutas cujas colorações ficavam entre roxo e vermelho, ricas em antocianina. Foram preparados extratos de: Casca de berinjela (Solanum melongena), Casca de Ameixa fresca (Prunus salicina), Jamelão (Syzygium cumini), Morango (Fragaria vesca), Casca de Uva roxa (Vitis vinifera) e Repolho roxo (Brassica oleracea rubra). O extrato da casca de beringela tem uma coloração vermelha e vária em meio ácido (vermelho claro) e meio básico (verde). O seu teste como corante em bala de gelatina não deu resultado satisfatório, pois a coloração não é visível na bala e deixa sabor residual. O extrato da casca da ameixa fresca teve um resultado semelhante ao da beringela.

O extrato da casca de uva roxa apresenta uma coloração vermelho ruby em meio ácido e em meio básico passa para uma coloração vermelha sangria. Ao ser adicionado à bala de gelatina para o teste de cor, não se obteve um bom resultado, sendo que a bala ficou com 
coloração semelhante ao barro. Ao utilizar a polpa e casca da uva roxa, no teste conjunto de sabor e cor, obteve-se um bom resultado, como está demonstrado na Figura 1.

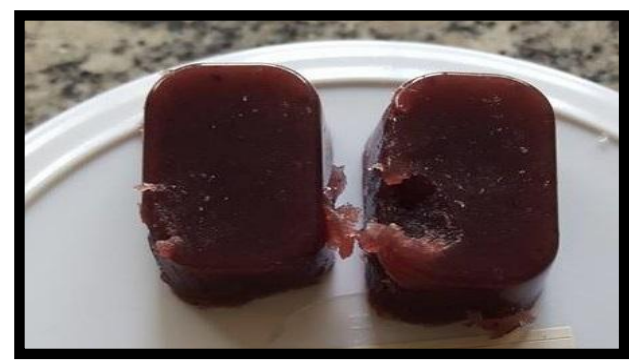

Figura 1 - Bala de gelatina de polpa de uva

O extrato obtido a partir do morango, para uso como corante, também não foi bem sucedido, pois a coloração adquirida pela bala foi influenciada por resíduos deixados pela fruta, e como teste conjunto para cor e sabor também não foi efetivo, o processo inicial não foi refeito. Ao serem misturados suco e gelatina e a mistura levada ao fogo, para o teste cor e sabor, a coloração vermelha se perde e adquiri-se uma coloração amarronzada, como pode ser vista na Figura 2.

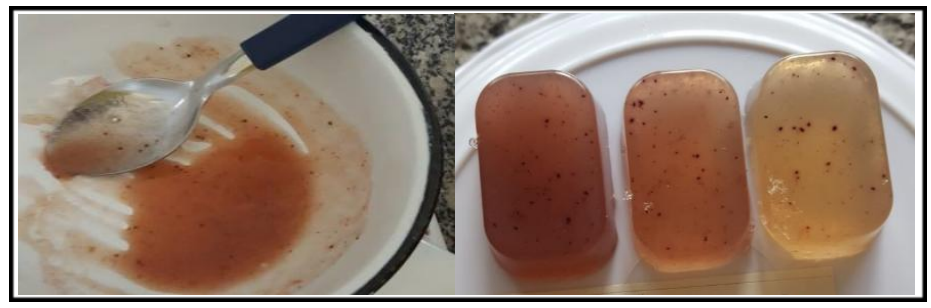

Figura 2- Á esquerda: mudança da coloração do morango com aquecimento; à direita: Atuação do corante na bala de gelatina.

O extrato feito com jamelão, para obtenção da cor não foi satisfatório, pois a coloração não é intensa, porém ao utilizar a polpa da fruta para saborizar e dá cor a bala de gelatina, obteve-se um melhor resultado, como demonstrado na Figura 3. Foi feito um teste preliminar voluntário para degustação da bala, com algumas pessoas, quanto ao sabor, e houve divergências de opiniões. Dessa forma, seu uso como saborizador requer uma análise mais profunda.

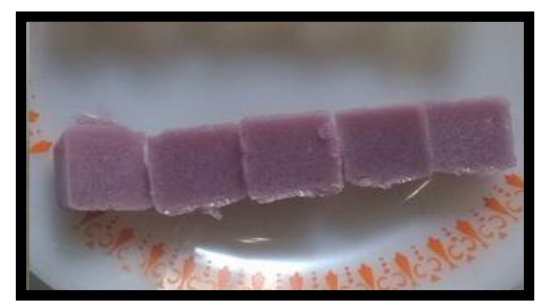

Figura 3- Bala de Jamelão.

$\mathrm{O}$ extrato do repolho roxo apresentou variação de cores em $\mathrm{pH}$ diferentes, apresentando coloração verde (meio básico) e coloração rosa (meio ácido), e ao misturar o básico com o ácido apresentou coloração azul. Como demonstrado na Figura 4. Obteve-se um bom resultado como corantes nas balas com todas as colorações.

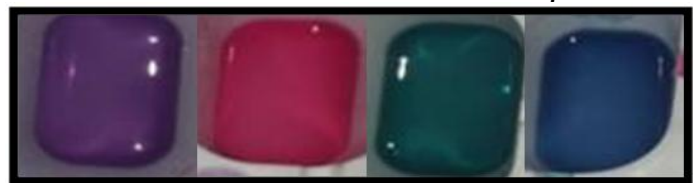

Figura 4 - Da esquerda para direita, extrato de repolho puro, em meio ácido, em meio básico e mistura do meio ácido e básico. 
Além da bala de gelatina, foram realizados outros testes para atuação do corante a base de extrato do repolho roxo em outros tipos de doce que utilizassem esses ingredientes, tais como: Clara de ovo (batido em neve), leite condensado, coco ralado úmido e seco. A clara do ovo interferiu na coloração devido ao seu pH básico, adquirindo uma coloração azul Oxford (muito escuro). O leite condensado não permitiu boa visualização por causa de sua cor branca, Figura 5.

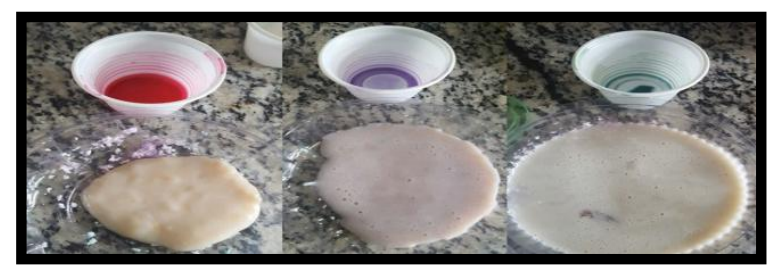

Figura 5 - Extrato de repolho roxo em diferentes meios, adicionado ao leite condensado.

Os testes com o coco ralado úmido foram satisfatórios, possibilitando obter coloração verde e rosa com o extrato do repolho roxo, porém a durabilidade e estabilidade precisam ser aprofundadas, pesquisando seu ao tempo de prateleira. Com o coco ralado seco houve dificuldade na visualização da cor em meio básico, e a mistura se deteriorou em tempo menor que o do coco ralado úmido, porém sua coloração em meio ácido foi mais intensa (Figura 6).

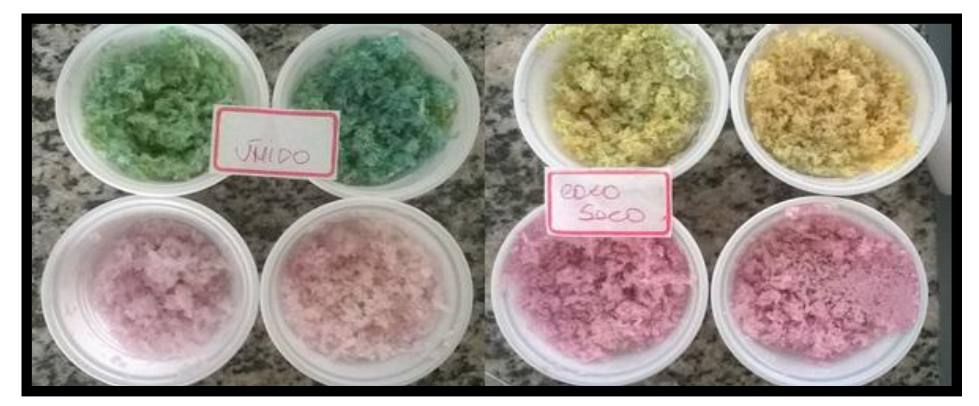

Figura 6 - A esquerda coco ralado úmido, com extrato de repolho e bicarbonato (verde), e extrato de repolho com gota de limão (rosa claro). A direita coco ralado seco, com extrato de repolho e bicarbonato (verde amarelado) e extrato de repolho com gota de limão (rosa).

\section{CONSIDERAÇÕES FINAIS}

O nosso trabalho permitiu formar algumas noções iniciais acerca do uso do pigmento (antocianina) de algumas frutas como corante natural, tanto em expectativas de coloração quanto ao possível sabor das balas. A continuidade do trabalho pode auxiliar a construção de um conhecimento mais aprofundado, tanto no que diz respeito às frutas que podem ser usadas como corantes assim como uma análise sensorial que auxilie quanto ao seu sabor e textura. Além disso, é interessante a realização de alguns testes quanto ao tempo de prateleira. A bala de gelatina saborizada com frutas como o jamelão e a uva precisam ter seus testes refeitos para ampliar o conhecimento adquirido com esse trabalho, quanto ao seu uso como corante, pois foram as espécies que deram os melhores resultados. Ademais, é importante também observar suas possíveis aplicações. As pesquisas realizadas nos permitiu adquirir algum conhecimento acerca do tema, estimulando nosso interesse para dar continuidade ao trabalho.

\section{REFERÊNCIAS}

CONSTANT, P.B.L; STRINGHETA, P.C; SANDI, D. CORANTES ALIMENTÍCIOS. Curitiba, v.20, n.2, p. 203-220, jul./dez., 2002. Disponível em: <http://revistas.ufpr.br/alimentos/article/view/1248/1048>. Acesso em: 28 de jul. 2017. 
PRADO, M. A.; GODOY,H. T.; CORANTES ARTIFICIAIS EM ALIMENTOS. Disponível em <http://serv-bib.fcfar.unesp.br/seer/index.php/alimentos/article/view File/865/744> Ano, 2003. Acesso em: 28 de jul. 2017.

TERCI, D. B. L.; ROSSI, A. V.; INDICADORES NATURAIS DE PH: usar papel ou solução? Disponível em < http://www.scielo.br/scielo.php?script=sci_arttext\&pid=S010040422002000400026> Ano, 2004. Acesso em 28 de março de 2016.

ZIMKE, D. BALA DE PECTINA: ELABORAÇÃO E AVALIAÇÃO SENSORIAL. Centro Universitário Univates, Curso Técnico em Química, Lajeado, Nov. 2014. Disponível em: 〈https://www.univates.br/tecnicos/media/artigos/Debora.pdf>. Acesso em: 28 de jul. 2017.

FOOD INGREDIENTS BRASIL, CORANTES NATURAIS. Disponível em: <http://revistafi.com.br/upload_arquivos/201606/2016060825792001465237434.pdf>

Revista- Fi No 18, 2011. Acesso em: 28 de jul. 2017.

OLIVEIRA, K.B,; AVELAR, M.M; CARLOS, L.A.; MARTINS, L.M; OLIVEIRA, K.G.; RODRIGUES, C.G. RETENÇÃO DE ANTOCIANINAS EM BALAS DE GOMA ADICIONADAS DE EXTRATO DE VINAGREIRA. Bento Gonçalves, RS, 2015. Disponível em: <http://www.ufrgs.br/sbctarseventos/gerenciador/painel/trabalhosversaofinal/SAL350.pdf $>$. Acesso em: 28 de jul. 2017. 